\title{
Medical supplies agencies and access to foreign currency in resource- limited settings: case studies from Sudan
}

Gamal Mohamed Ali ${ }^{1}$

Pamela Steele Associates (PSA), Addis Ababa, Ethiopia (Correspondence to: Gamal Ali: gamalkh@hotmail.com).

Citation: Mohamed Ali G. Medical supplies agencies and access to foreign currency in resource-limited settings: case studies from Sudan. East Mediterr Health J. 2022;28(1):74-77. https://doi.org/10.26719/emhj.22.004

Received: 04/01/21, accepted: 15/06/21

Copyright (C) World Health Organization (WHO) 2022. Open Access. Some rights reserved. This work is available under the CC BY-NC-SA 3.0 IGO license (https://creativecommons.org/licenses/by-nc-sa/3.o/igo).

\section{Introduction}

Throughout the world, medicines are one of the key elements in the success of the modern health care system (1). However, the lack of access to essential medicines in developing countries is one of the most pressing global health problems. The World Health Organization has reported that people lack access to essential medicines where they cannot obtain the product they need to prevent or treat a medical condition (2). This could be as a result of a number of reasons, such as unavailability of the product needed.

Access to convertible currency and international banking transactions is one of the essential elements for sustaining international procurement of pharmaceuticals. This is more so for public medical supplies agencies (MSAs) in developing countries (Figure 1), where in many cases governments may not be in a position to easily provide foreign currency $(3,4)$. This paper proposes the signing of currency swap agreements between governments and donors, international nongovernmental organizations or United Nations (UN) agencies as a strategy to improve access to essential medicines in developing countries, especially in sub-Saharan Africa. To consolidate this proposal, two case studies from Sudan are presented as success stories. These two case studies illustrate innovative arrangements that the Government of Sudan has implemented with an international nongovernmental organization and a UN agency. The government has managed to secure some of its needed foreign currency via the national and state revolving drug funds (RDFs): the National Medical Supplies Fund (NMSF) and RDF-Khartoum State respectively. These foreign currency swap arrangements have contributed to improvements in access to quality medicines at affordable prices (less than $50 \%$ of the alternative sources).

The remaining part of this paper describes these two case studies. The paper concludes by summarizing the two case studies and presenting lessons learned.

\section{Case reports}

Case 1: Currency swap agreement between the revolving drug fund and Save the Children (United Kingdom)

The RDF of Khartoum State (RDF-KS) was accomplished with the technical and financial support of Save the Children (United Kingdom), better known as SC (UK), to improve chronic shortages of medicines in public health facilities in the early 1980s. After the first capital investment was made by SC (UK), since 1989 the RDFKS has been using its own revenues generated from pharmaceutical sales to procure more affordable medicines. The RDF-KS serves more than 5 million patients annually, with more than 565.34 billion Sudanese pounds (SDGs) (US\$13.00 million) annual turnover (5). Khartoum State has high level availability of essential medicines at affordable prices (6) and this is attributed, among other things, to the access to foreign currency through the RDF-KS (see below).

The devaluation of the Sudanese pound during 1991, by $200 \%$ and later by $723 \%$ in 1992 , resulted in the first decapitalization of the RDF-KS (Awadelkari MA, Idrees A, MustafaSM.Evaluation report: Khartoum comprehensive child care programme. Ministry of Health, Khartoum State; unpublished report, 1996). For instance, during this period, the RDF-KS lost about US\$ 1.2 million from its initial capital of US\$ 2.6 million (i.e. 46\%) when large sums of local currency were deposited in the bank (7). As a response to this loss, the Federal Ministry of Finance and SC (UK) signed a currency swap agreement through which local funds generated from RDF-KS medicine sales and allocated for overseas procurement of medicines are swapped for the equivalent foreign currency allocation at the SC-Sudan office. According to the agreement (1992-2001), revenues collected were regularly converted to foreign currency because medicines were usually imported. During this period, the RDF-KS implemented a monthly currency swap with SC (UK).

By 2002, and as a result of economic improvement after oil production, the RDF-KS enjoyed free circulation of convertible currency to meet its need for foreign 
Figure 1 Schematic diagram depicting the operations of the medical supplies agencies in Sudan and their sources of finance as of 2021
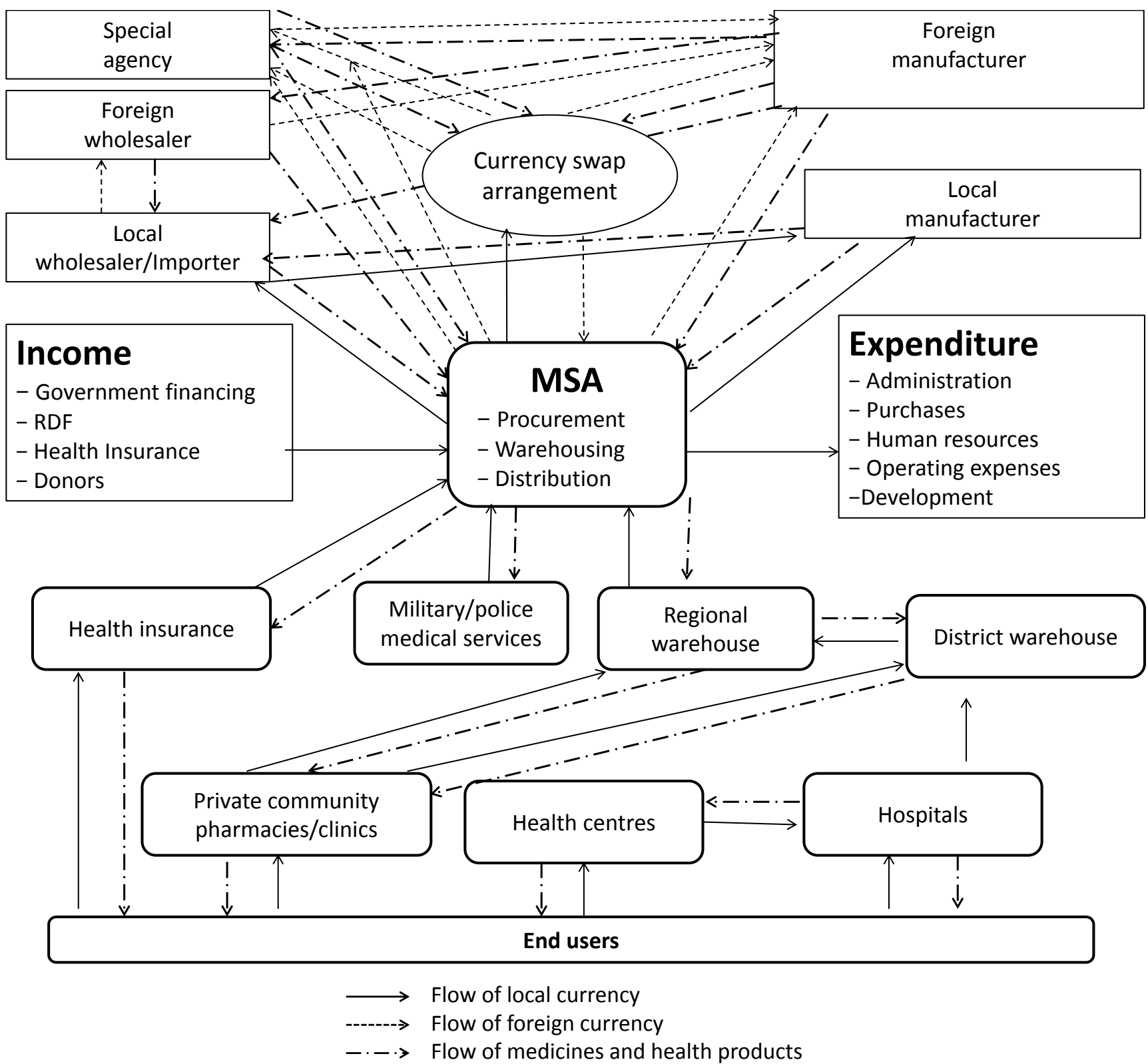

currency directly from the market (8). However, in 2009, the RDF-KS stopped importing medicines and started fulfilling its needs from the local market in compliance with new national regulations.

\section{Case 2: Agreement between the National Medical Supplies Fund and the United Nations Development Programme}

The NMSF is the autonomous national agency for procurement, storage and distribution of medical supplies for the public sector in Sudan. The mandate of NMSF is to ensure that essential medicines and medical supplies of proven safety, efficacy and quality are available to the population at reasonable prices.

The NMSF, at the time of writing, had revolved for around 30 years without the injection of additional funds from the government or from donors. The NMSF fully covers its procurement (US\$350.03 million in 2018), operational (US\$18.53 million in 2018) and developmental (US\$ 18.69 million in 2018) costs from its own revenues. For example, the NMSF has established branches in 17 out of 18 states at a cost of more than US\$ 36 million from its own resources. Without technical donor support or financial support from the government, the NMSF has moved from limited access (a $46 \%$ availability rate) to affordable, quality medicine and a reliable supply chain, with a medicine availability rate of more than $90 \%$ since 2013. By the end of 2018, more than 2780 out of 3370 health facilities received regular supply of medicines through the RDF.

Following the secession of South Sudan, Sudan has experienced a significant loss in oil revenues and exports and, as a result, a decline in growth. The crisis is affecting 
the availability of foreign currency, with subsequent effects on the foreign exchange rate.

The NMSF and the United Nations Development Programme (UNDP) have made considerable progress in the management of Global Fund commodities. This fruitful collaboration has inspired the NMSF to propose a new cooperation agreement with UNDP. The proposed area of cooperation includes setting up a currency swap mechanism to overcome constraints in accessing foreign currency and to provide a solution to the banking problems as a result of American sanctions on Sudan. The Government of Sudan and UNDP signed the agreement on 10 March 2016 for the procurement of medicines and medical products for the period 2016-2019.

According to the agreement, local funds generated from NMSF medicine sales and allocated for overseas procurement of medicines are swapped for the equivalent foreign currency allocation at the UNDP Sudan office. The NMSF submits a purchase order to the UNDP, UNDP purchases, on behalf of NMSF, the required medicines from abroad using the allocated amount equivalent in US\$. Unfortunately, the maximum annual budget that UNDP could absorb to cover its operation in Sudan was US\$ 20 million (i.e. $15 \%$ of the NMSF's annual needs for foreign currency). Due to this limited budget available for activities of the UNDP in Sudan, the NMSF used the allocated budget to import the most beneficial life-saving medicines, such as digoxin, insulin and adrenaline injections. More than 2.3 million patients benefited from this agreement in two years.

\section{Conclusion}

This paper presents two models of the currency swap mechanism. The first is the RDF-KS model, where the government of Sudan allowed SC (UK) to deposit foreign currency into the RDF-KS bank account to be used for the import of medicines. The second is the NMSF model; in this model, NMSF deposited local currency to the
UNDP account on a monthly basis. The UNDP allocated the equivalent amount in US dollars to be used for the purchase of medicines for NMSF. The first model was more flexible because the RDF-KS itself purchased its medicines.

Both NMSF (2016-2019) and the RDF-KS (1992-2001) maintained the prescription cost to end users at half the prices charged in private pharmacies while making a surplus to finance its operating and development costs. Moreover, the availability of foreign currency allowed a regular supply of medicines from abroad to these organizations, and consequently to public health facilities. Finally, the availability of foreign currency protected the RDFs at both national and state levels against excessive losses by devaluation of local cash in hand as a result of local currency inflation. The currency swap mechanism has, therefore, played a very important role in the access to quality medicines in Sudan.

The lessons learned are as follow: (1) Donors and development organizations wishing to set up effective RDFs may need to be innovative in responding to constraints that arise with such projects (2). Access to foreign currency is one constraint; By setting up a currency swap mechanism or any other kind of arrangement, governments, donors, international development organizations and UN agencies can replicate or modify the mechanism that the Government of Sudan has successfully implemented to ensure timely access to foreign currency. This is important because, from the available literature on RDFs (see, for example, 9-11), there seems to be no evidence of the application of this mechanism between donors and governments in situations where the RDFs are supported by international donors.

\section{Funding: None.}

Competing interests: The author of this case study was the general manager of the Revolving Drug Fund (19942002) and Director General of the National Medical Supplies Fund (2010-2019).

\section{References}

1. Monitoring the building blocks of health systems: a handbook of indicators and their measurement strategies. Geneva: World Health Organization; 2010 (www.who.int/healthinfo/systems/WHO_MBHSS_2010_full_web.pdf, accessed 1 July 2019).

2. The world medicines situation. Geneva: World Health Organization; 2004 (WHO/EDM/PAR/2004.5).

3. Wang'ombe JK, Mwabu GM. Economics of essential drugs schemes: the perspectives of the developing countries. Soc Sci Med. 1987;25(6):625-30. doi:10.1016/0277-9536(87)90088-8

4. Knippenberg R, Alihonou E, Soucat A, Oyegbite K, Calivis M, Hopwood I, et al. Implementation of the Bamako Initiative: strategies in Benin and Guinea. Int J Health Plann Manage. 1997 Jun;12 (Suppl. 1):S29-47. doi:10.1002/(sici)10991751(199706)12:1+3.3.co;2-1

5. Annual report of the revolving drug fund. Khartoum: Ministry of Health, Khartoum State; 2018.

6. Witter S. Achieving sustainability, quality and access lessons from the world's largest revolving drug fund in Khartoum. East Mediterr Health J. 2007;13(6):1476-85. doi:10.26719/2007.13.6.1476

7. Mohamed Ali GK. Management of revolving drug fund: experience of Khartoum State - Sudan [dissertation]. Bradford: University of Bradford; 2000.

8. Mohamed Ali GK. The impact of the RDF on accessibility of medicines: experience of Khartoum State, Sudan. Saarbrücken, Germany: Lambert Academic Publishing; 2010. 
9. Murakami H, Phommasack B, Oula R, Sinxomphou S. Revolving drug funds at front-line health facilities in Vientiane, Lao PDR. Health Policy Plan. 2001 Mar;16(1):98-106. doi:10.1093/heapol/16.1.98

10. Uzochukwu BS, Onwujekwe OE, Akpala CO. Effect of the Bamako-Initiative drug revolving fund on availability and rational use of essential drugs in primary health care facilities in south-east Nigeria. Health Policy Plan. 2002 Dec;17(4):378-83. doi:10.1093/ heapol/17.4.378

11. Jitta J, Reynolds Whyte S, Nshakira N. The availability of drugs: what does it mean in Ugandan primary care. Health Policy. 2003 Aug;65(2):167-79. doi:10.1016/s0168-8510(03)00003-4 